\title{
Sepsis urológica secundaria a cistitis enfisematosa
}

\author{
Molina Suárez JL*, Abengozar García-Moreno A*, Ramirez Zambrana A*, Laguna Álvarez E*, \\ Fernandez Alarcón L**, Arroyo Masa MI***. \\ *Servicio de Urologia. **Servicio de Radiodiagnóstico. ***Servicio de Urgencias. \\ Hospital Universitario Infanta Cristina. Badajoz. \\ Actas Urol Esp. 2008;32(8):858-860
}

\section{RESUMEN}

\section{SEPSIS UROLÓGICA SECUNDARIA A CISTITIS ENFISEMATOSA}

La cistitis enfisematosa es una patología infecciosa rara cuyo diagnóstico requiere un alto grado de sospecha ante una clínica compatible en pacientes con factores de riesgo que le hagan susceptible, y unos datos radiográficos que confirmen dicha sospecha. Habitualmente evolucionan bien con un diagnóstico precoz y un manejo adecuado.

Presentamos un caso de cistitis enfisematosa en un paciente de 75 años, diabético, que evoluciona a un estado séptico tratado de forma conservadora.

Palabras clave: Enfisematosa. Cistitis. Sepsis.

\section{ABSTRACT}

\section{UROSEPSIS DUE TO EMPHYSEMATOUS CYSTITIS}

Emphysematous cystitis is a rare infectious disease which diagnosis requires a high grade of suspicion in patients with compatible clinical symptoms, risk factors that make them susceptible, and a radiographic examination that confirm the suspicion. Patients usually have a favorable evolution with an early diagnosis and an appropriate management.

We present a 75 years old diabetic patient with emphysematous cystitis that develops into an urosepsis treated in a conservative management.

Keywords: Emphysematous. Cystitis. Urosepsis.

$\mathrm{L}^{2}$ a cistitis enfisematosa es una entidad patológica poco frecuente definida por la existencia de gas en la pared vesical debido a la infección de la vejiga por microorganismos productores de gas.

Esta enfermedad predomina en los pacientes inmunodeprimidos, sobretodo diabéticos, siendo más común en mujeres.

La presentación clínica es variada, pero suele ser necesario un alto índice de sospecha, sobretodo en la población susceptible, para su diagnóstico.

\section{CASO CLÍnICo}

Varón de 75 años con diabetes mellitus tipo 2 que durante su estancia hospitalaria para la colocación de un stent coronario sufre retención aguda de orina que precisa sondaje vesical. Cinco días más tarde se retira la sonda y se prescribe tratamiento antibiótico empírico con Amoxicilina-Clavulánico además de su tratamiento habitual con: Atenolol, AAS, Clopidogrel, Atorvastatina, Repaglinida y Demotan. Desde entonces presenta tenesmo, disuria intensa y orina ligeramente hematúrica, motivo por el que regresa al hospital 2 días después por dolor en hipogastrio y mal estado general, presentando a la exploración física marcado globo vesical, abdomen distendido y timpanizado, hipotensión $(105 / 40)$ y algunos crepitantes pulmonares.

En las pruebas complementarias iniciales importa reseñar glucemia 406, 10.600 leucocitos con 89\% de segmentados, nitritos positivos en orina con 500 leucocitos $/ \mu \mathrm{l}$ y 250 eritrocitos $/ \mu \mathrm{l}$, sedimento con 


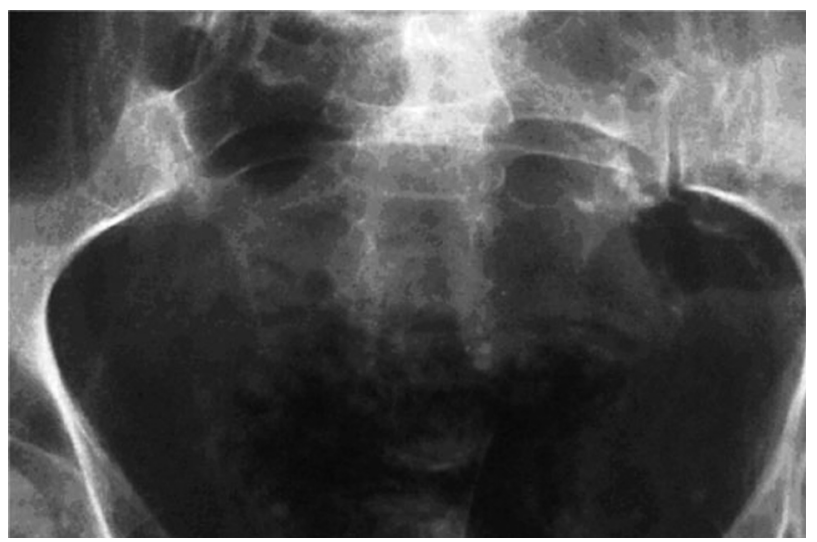

FIGURA 1. Rx simple aparato urinario: Gas a nivel vesical.

50-100 leucocitos/campo y más de 100 hematíes/campo, y Rx simple de aparato urinario donde se aprecia gas insinuando la silueta vesical (Figs. 1).

Realizado sondaje vesical para resolver la retención aguda de orina se obtiene orina ligeramente hematúrica y neumaturia significativa, por lo que se practica TAC abdominopélvico sin contraste y con él a través de la sonda de Foley. En la fase del estudio sin contraste se aprecia abundante gas a nivel vesical, y el segundo tiempo con contraste pone en evidencia gas en todo el espesor de la pared y el espacio perivesical (Figs. 2 y 3 ).

Se instaura tratamiento conservador con fluidoterapia y cobertura antibiótica con ImipenemCilastatina intravenoso cada 8 horas.

El paciente evoluciona con hipotensión mantenida, oliguria y fiebre, por lo que es trasladado a la Unidad de Cuidados Intensivos.

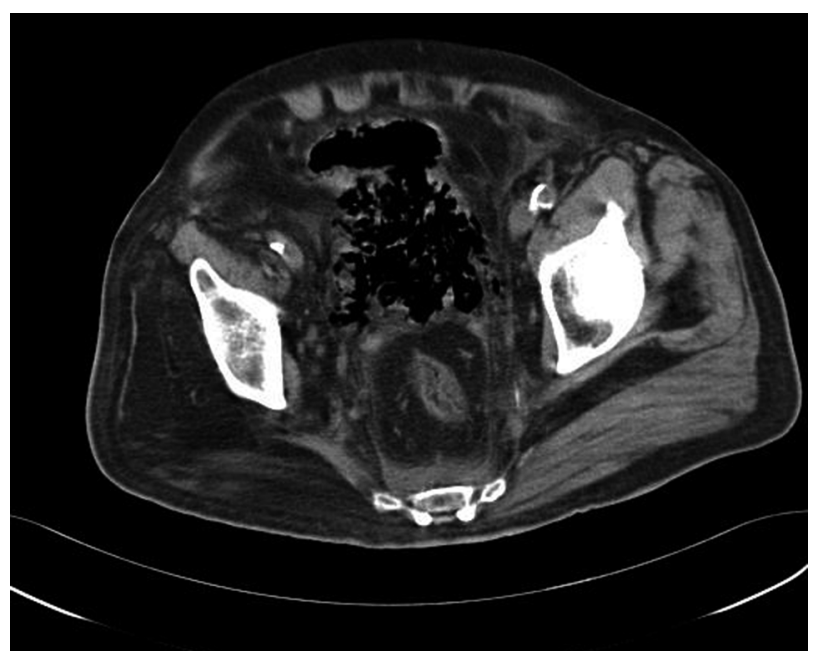

FIGURA 2. TAC sin contraste: Presencia de aire en la región vesical.

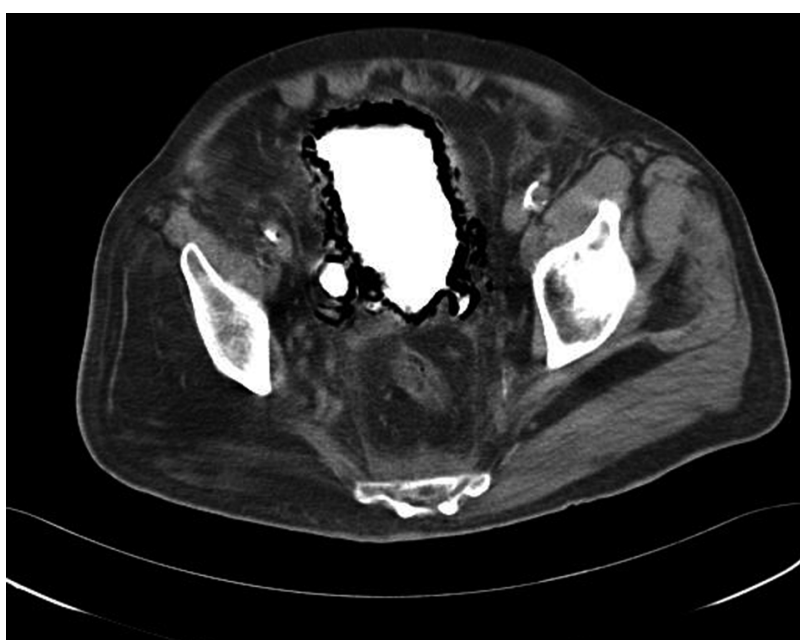

FIGURA 3. TAC con contraste: Se observa gas en el interior y por fuera de la pared vesical, además de dos divertículos.

Durante su estancia en U.C.I. mantiene fiebre, dolor en hipogastrio y tendencia a la hipotensión. Ante la persistencia del cuadro clínico se realiza TAC de control en el que se obseva pared vesical engrosada con aire en su interior pero en menor cuantía, aunque debido a la mala evolución clínica se asoció tratamiento antifúngico con Voriconazol.

El urocultivo se informa negativo mientras que en el hemocultivo aparece Klebsiella pneumoniae.

La evolución fue favorable, por lo que fue trasladado a la planta de Urología y posteriormente dado de alta con sonda (Figs. 4 y 5).

\section{DISCUSIÓN}

La cistitis enfisematosa es una infección de la vejiga que se caracteriza por la presencia de gas en la pared vesical.

Afecta con mayor frecuencia al sexo femenino y pacientes con diabetes mellitus ${ }^{1}$. Otras entidades asociadas son infecciones urinarias previas, trasplante renal, divertículos vesicales, vejiga neurógena, etc.

La sintomatología suele ser inespecífica, presentando síntomas de infección urinaria de vías bajas como disuria, frecuencia, hematuria y dolor abdominal bajo. Más raro es la presencia de neumaturia o la presencia de gas en los tejidos que puede ser palpado en los flancos o en ingles. El cuadro se puede complicar con una propagación del proceso infeccioso e incluso con el desarrollo de un shock séptico $^{2,3}$. 


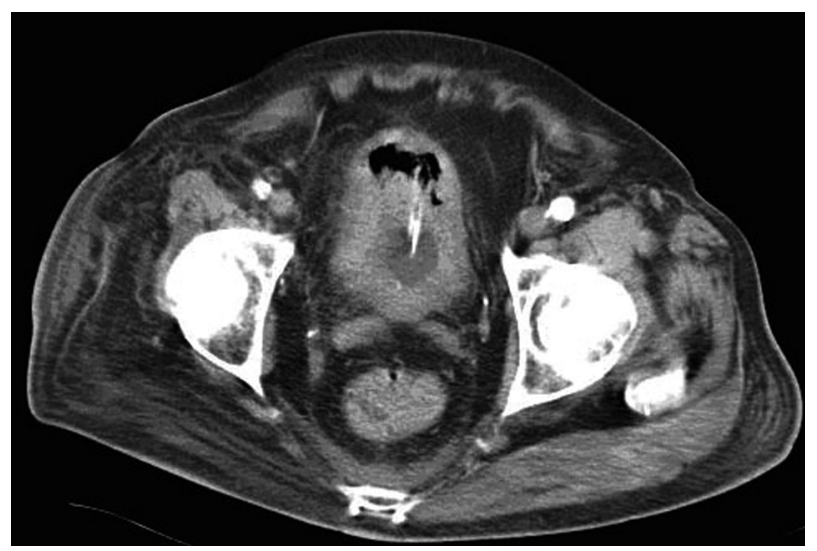

FIGURA 4. TAC control sin contraste: Gas en la región correspondiente a la vejiga.

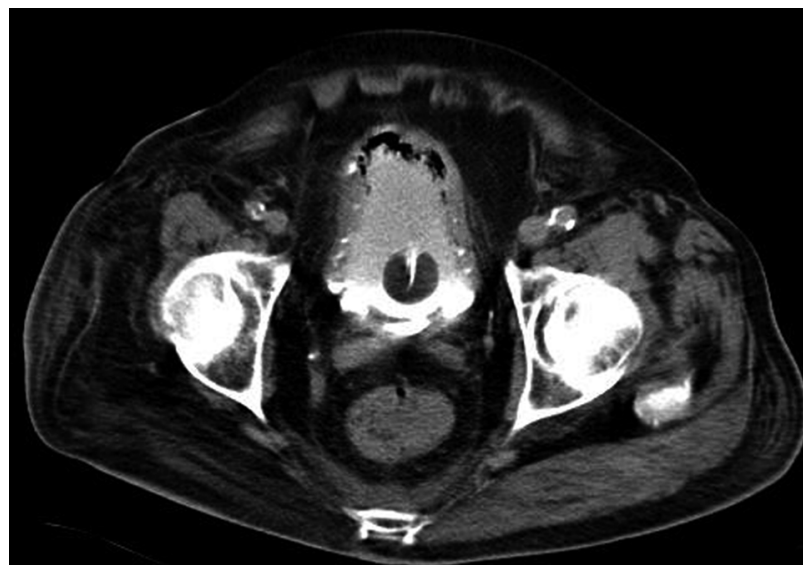

FIGURA 5. TAC control con contraste: Gas en el interior de la pared vesical en menor cuantía que en TAC inicial.

Su etiología es habitualmente bacteriana, principalmente E. Coli, aunque también puede estar producido por Klebsiella pneumoniae, como es el caso del paciente que presentamos, Enterobacter, Clostridium perfringens y especies fúngicas como Candida ${ }^{1,4}$.

Para su diagnóstico son imprescindibles los datos radiográficos que informen de la presencia de gas en la pared vesical, pudiendo aparecer también gas en el interior de la vejiga ${ }^{5}$.
El diagnóstico diferencial debe realizarse principalmente con la fístula enterovesical y con la yatrogenia por instrumentación de la vía urinaria ${ }^{3}$.

Estos pacientes requieren en su manejo terapéutico drenaje urinario mediante sonda vesical, tratamiento antibiótico adecuado y control de la glucemia en los casos que así lo requieran ${ }^{5,6}$. En el caso en que el agente sospechado sea un hongo el tratamiento debe incluir un antifúngico i.v. o intravesical. El manejo quirúrgico queda reservado para aquellos pacientes que no respondan al tratamiento médico.

\section{REFERENCIAS}

1. Bobba RK, Asura EL, Sarna PS, Sawh AK. Emphysematous cystitis: an unusual disease of the Genito-Urinary system suspected on imaging. Ann Clin Microbiol Antimicrob. 2004;3:20.

2. Wu TT, Huang JS, Huang JK, Lee YH. Focal emphysematous cystitis arising in a diverticulum: a case report. J Urol. 1996;155 (2):643.

3. Bañón Pérez VJ, García Hernández JA, Valdelvira Nadal P, Nicolás Torralba JA, Server Pastor G, Coves R, Martínez Barba E, et al. Perforación vesical intraperitoneal en el transcurso de una cistitis enfisematosa. Actas Urol Esp. 2000;24(6):501-503.

4. Marvalyn Decambre MD, Peter Albertsen, MD, Scott Rutchik, MD. Emphysematous cystitis: Caveats of complex presentations. Infect Urol. 2002;15(4):19-21

5. Perlemoine C, Neau D, Ragnaud JM, Gin H, Sahnoun A, Pariente JL, et al. Emphysematous cystitis. Diabetes metab. 2004;30(4): 377-379.

6. Sakamoto F, Taki H, Yamagata T, Tsukurimichi S, Ikeda M, Su giura T,et al. Emphysematous cystitis with severe hemorrhagic anemia resulting from diabetes mellitus type 2. Intern Med. 2004;43(4):315-318.

Correspondencia autor: Dr. J.L. Molina Suárez

Servicio de Urología. Hospital Universitario Infanta Cristina Avda. de Elvas, s/n - 06006 Badajoz

Tel.: 924218100

e-mail autor: juarlu_moli@hotmail.com

Información artículo: Nota Clínica

Trabajo recibido: febrero 2007

Trabajo aceptado: marzo 2007 